\title{
Study of a typical photovoltaic greenhouse in Hainan tropical island
}

\author{
Zhiwu Ge ${ }^{1, a}$, Yue $\mathrm{Li}^{2, \mathrm{~b}}$ Chengling Bian ${ }^{3, \mathrm{c}}$ \\ ${ }^{1}$ Hainan normal University, Automation Department, No. 99, Long Kun south road, Haikou, China \\ ${ }^{2}$ Mechanics Department, No. 58, people's road, Haikou, China \\ ${ }^{3}$ Hainan normal University, Physics Department, China \\ ahnnu13@163.com, byuehaid@126.com, chnsf11@qq.com
}

Keywords: Photovoltaic, power generation, agriculture, greenhouse, plant, temperature distribution, light intensity.

Abstract. In the combination process of photovoltaic electric power generation with agriculture, there are many problems brought out, even in some important demonstration projects in Hainan island. In order to solve some of these problems, we detected and analyzed part of the plant growth factors in a typical project built in 2014. We measured the temperature distribution of plants and photovoltaic panels in the greenhouse and on the open land, were also tested the light intensity in the greenhouse and near panels. The infrared temperature distribution image and light intensity curve showed that the temperature has no obvious differences because of wind, but the light intensity reduced to $1 / 20$ to $1 / 8$ of total sunlight intensity outside the greenhouse, too weak for many plants to growth well. These detection results are very important for photovoltaic greenhouse design.

\section{Introduction}

In recent years, under national policy support, solar energy has become a fast growth energy application form all over the world. Our country also spare no effort in the development of the photovoltaic power generation, the government support building more photovoltaic power station, encourage and facilitate infiltration of photovoltaic applications to other industries at the same time.

After 10 years of rapid expansion, the monotonous Photovoltaic power generation business has just do hard to get the support of local government currently, combining photovoltaic (pv) with other industries has become a suitable way, and is also the encouraged direction of the policy, "agriculture + $\mathrm{pv}$ "mode is one of them. Because of the common and complementary aspect of photovoltaic (pv) and agriculture on the land use, the industry has been seeking a combination for breakthrough, making it one of the important developing direction currently.

In this paper, a typical photovoltaic greenhouse in the 20MW modern agriculture power station will be introduced, the station located in a small village in TunChang county on Hainan island[1,2].

\section{Introduction of the agriculture power station}

The project is approved by the state ministry of finance, ministry of science and technology, the national development and reform commission, as one of the 2012 annual "golden sun" demonstration project, and it's also a key project of Hainan province in 2013[1,2].

The agriculture power station project capacity is $20 \mathrm{MW}$, polycrystalline silicon components were installed, component brackets were installed in a fixed Angle, the total investment is about 180 million Yuan, the actual environmental protection investment is 260000 Yuan.

The total project (Fig.1) covers an area of about $420 \mathrm{mu}$. The project adopts the combination of agriculture and photovoltaic power generation, planting and breeding under the solar panels, making full use of climate and land conditions, implement the three-dimensional efficient utilization of the sunlight and land resources[2].

In this project, vegetables and herbs were planted in the photovoltaic greenhouse(Fig.2), or simply planted under Photovoltaic panels(Fig.3). 


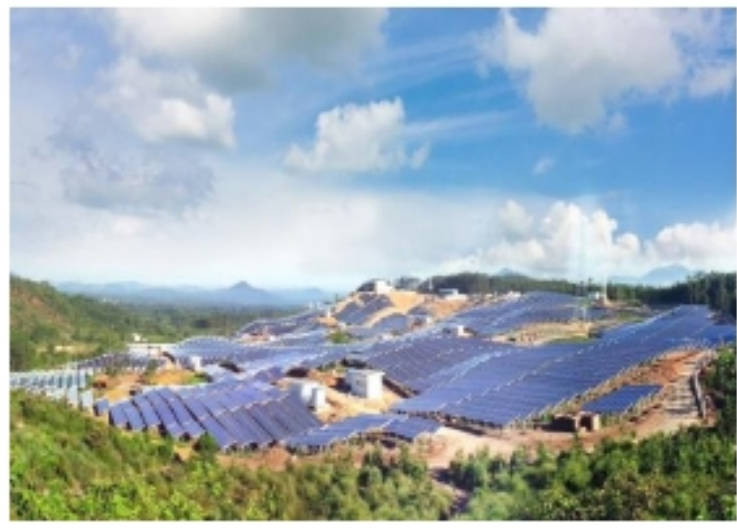

Figure 1. Bird's-eye view of the project

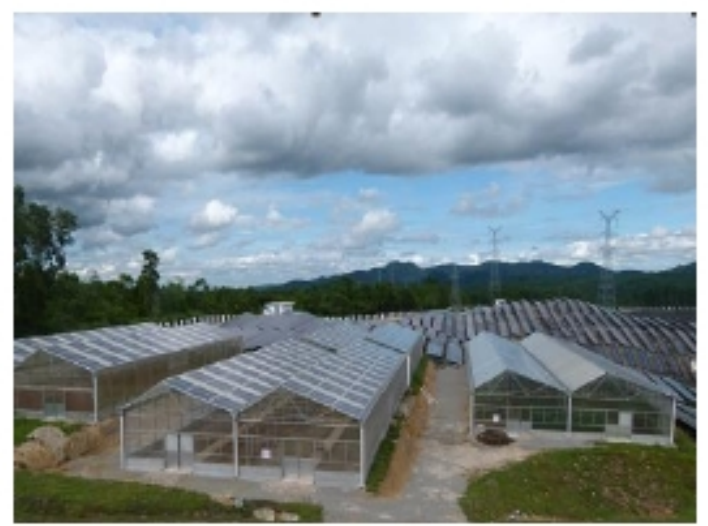

Figur e 2. Photovoltaic greenhouse

Many kinds of vegetables have been planted in the photovoltaic greenhouse, until now, local farmers have completed planting in four greenhouses, a total of about 2 acres of balsam pear, cucumber, eggplant, beans, cabbage and other vegetables[1,2].

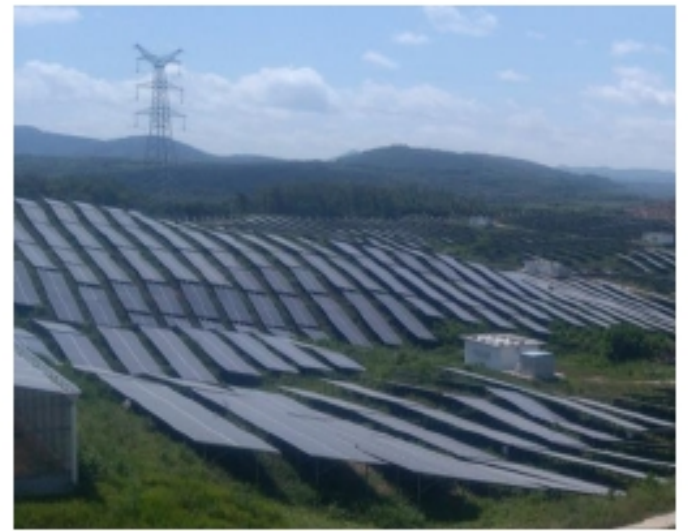

Figure 3. Photovoltaic panels and plant below

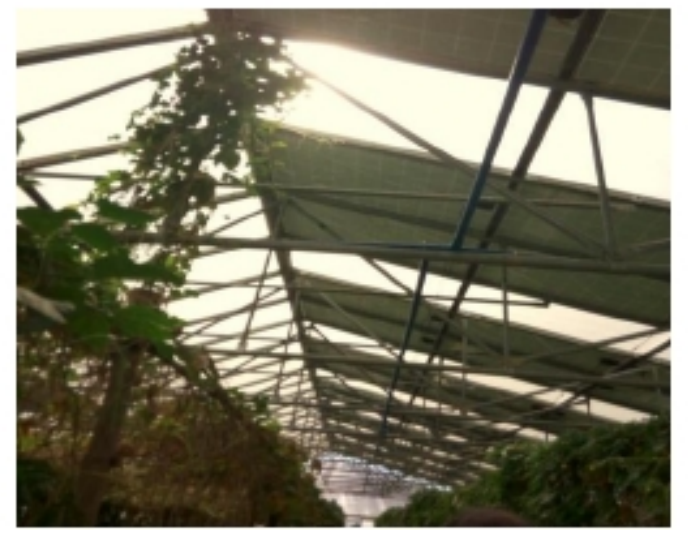

Figure 4. Withered Plants in photovoltaic greenhouse

At the same time, many kinds of herbs have been planted under Photovoltaic panels as shown in Fig.3. These panels are set $0.5 \mathrm{~m}$ to $2.5 \mathrm{~m}$ in height to test the different effect.

Local farmers have also completed planting 200 acres herb (Alpinia oxyphylla), $30 \mathrm{mu}$ sweet potato, 10 acres melon, and 100 lemon plant.

Although a lot of plants have been planted, there are a lot of problems left to study, many plants don't grow as well as under the natural state in farmland. Because of the poor sunlight in the greenhouse, the plants in photovoltaic greenhouse become withered as shown in Fig.4, so it's necessary to study the physical conditions in greenhouse or under panels.

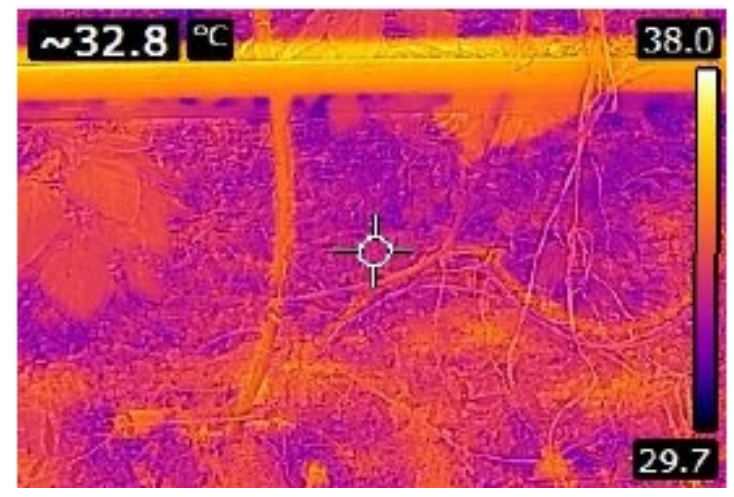

Figure 5. Temperature distribution of plants in the greenhouse

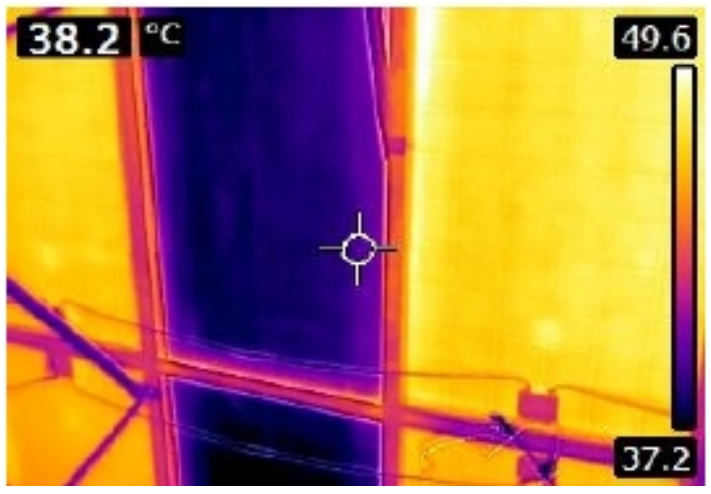

Figure 6. Temperature distribution of panels in the greenhouse 


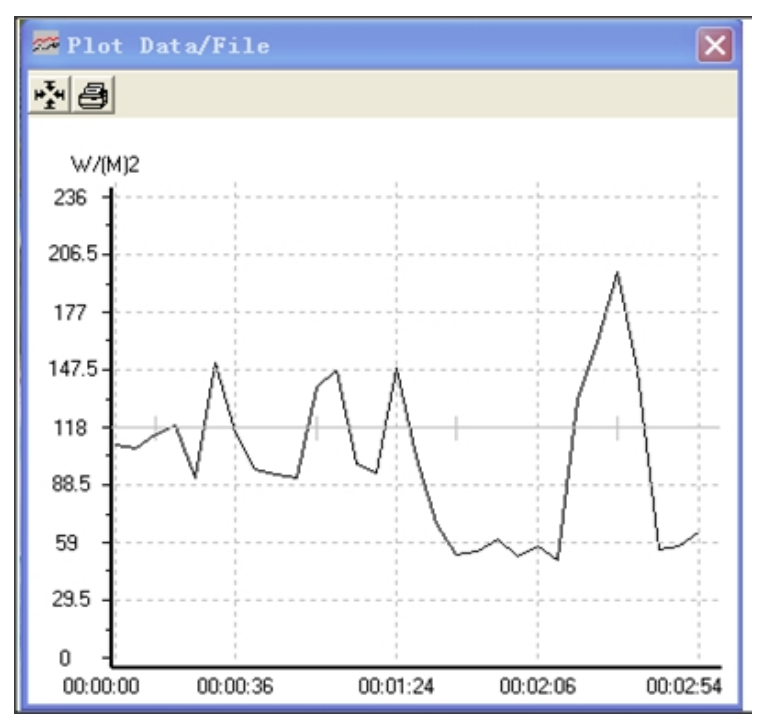

Figure 7. Light intensity in the greenhouse

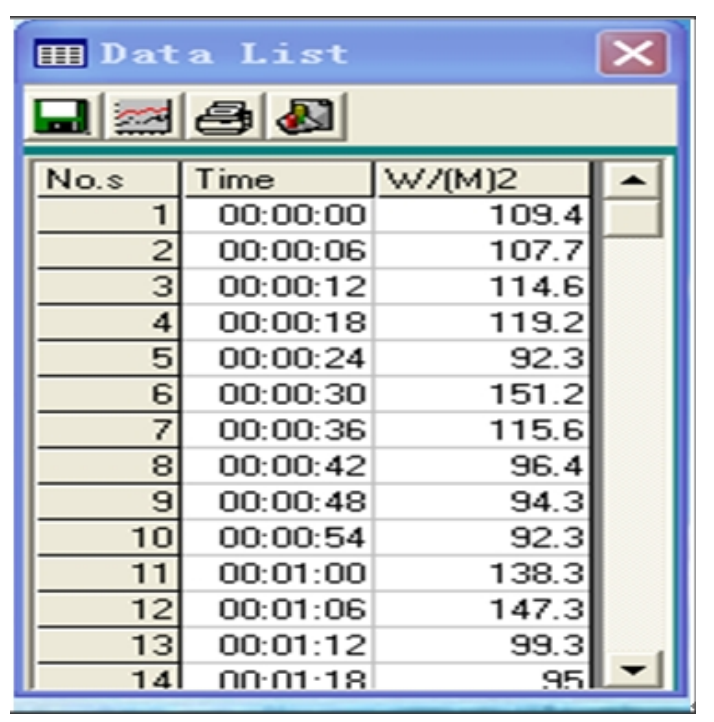

Figure 8. Part of the light intensity data in FIG.8

Fig.5-Fig.6 shows the temperature distribution of plants and panels in the greenhouse, and Fig.7-Fig. 8 light intensity in the greenhouse, the detection was taken by using light intensity meter and infrared thermal imager.

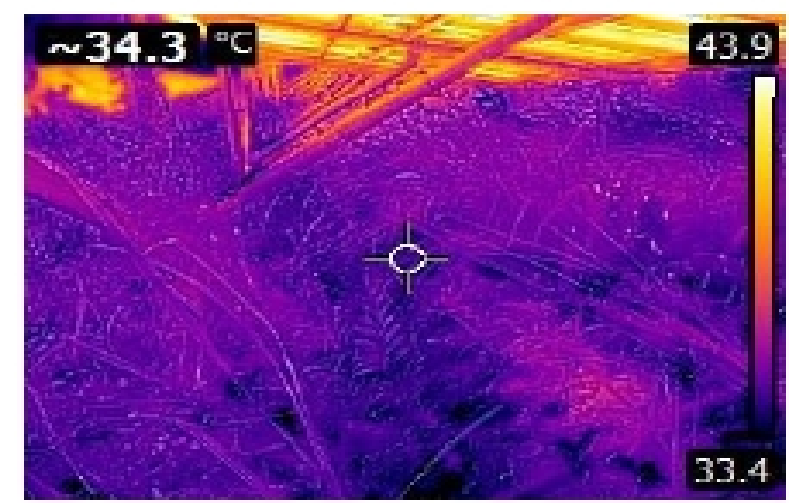

Figure 9. Temperature distribution of plants under panels

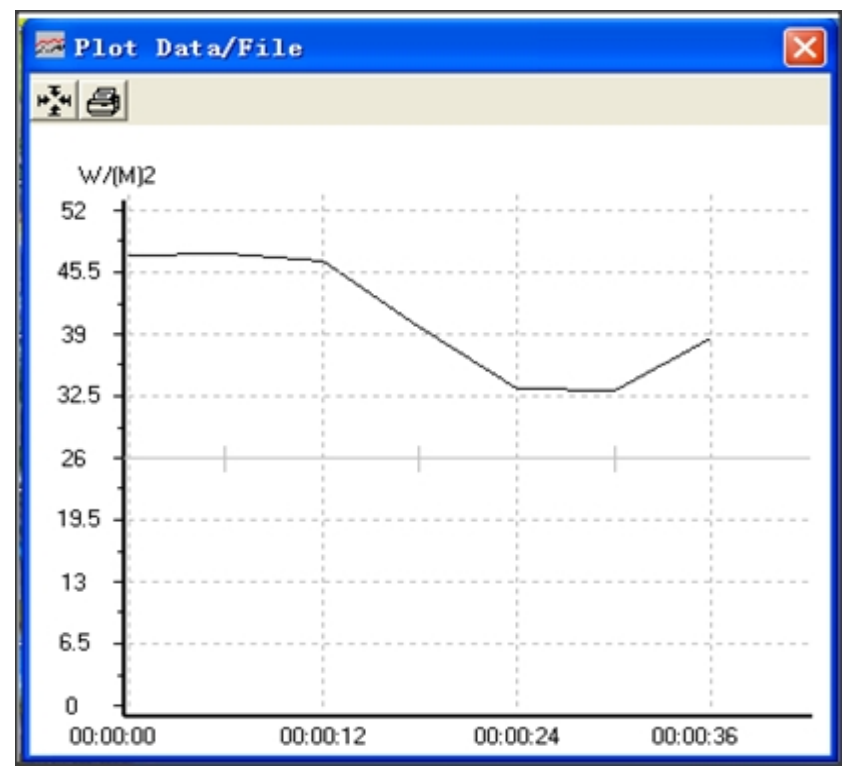

Figure 11. Light intensity under panels back side

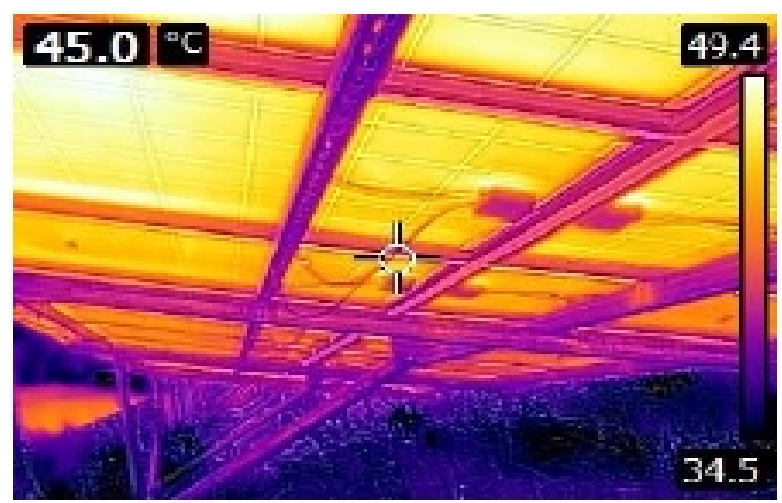

Figure 10. Temperature distribution of panels back side

\begin{tabular}{|c|c|c|c|}
\hline 国Dat & a List & & $x$ \\
\hline ㅁ. & 奇 8 & & \\
\hline No.s & Time & $W /(M) 2$ & \\
\hline 1 & $00: 00: 00$ & 47.2 & \\
\hline 2 & $00: 00: 06$ & 47.4 & \\
\hline 3 & $00: 00: 12$ & 46.6 & \\
\hline 4 & $00: 00: 18$ & 39.8 & \\
\hline$\overline{5}$ & $00: 00: 24$ & 33.2 & \\
\hline 6 & $00: 00: 30$ & 33 & \\
\hline 7 & $00: 00: 36$ & 38.7 & \\
\hline 8 & $00: 00: 42$ & 853.2 & \\
\hline
\end{tabular}

Figure 12. Part of the light intensity data in Fig. 12 
Fig.9-Fig.10 shows the temperature distribution of panels and plants under panels.

Fig.11-Fig.12 light intensity under panels.

Fig.13 shows the temperature distribution of panels surface and plants beside panels.

Fig.14 shows the sunlight intensity near panels detected.

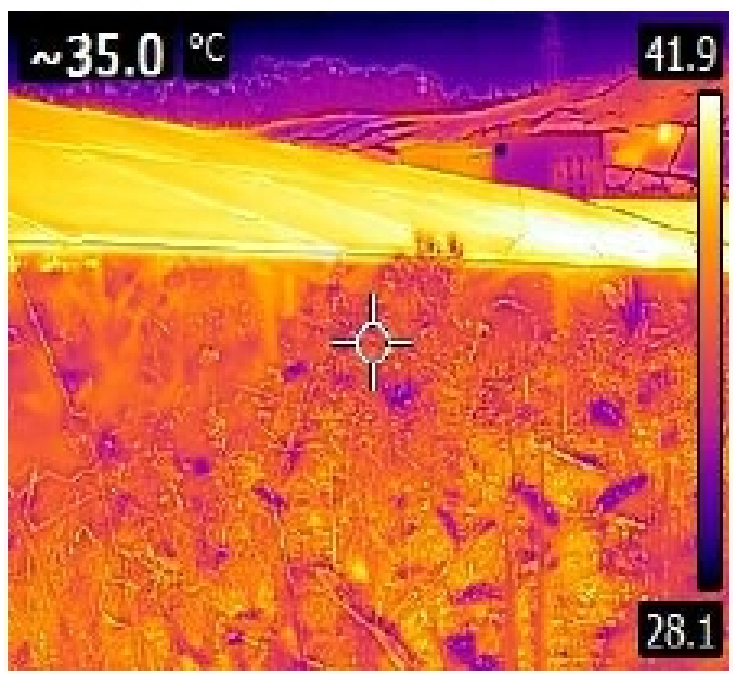

Figure 13. Temperature image of plants and panels surface

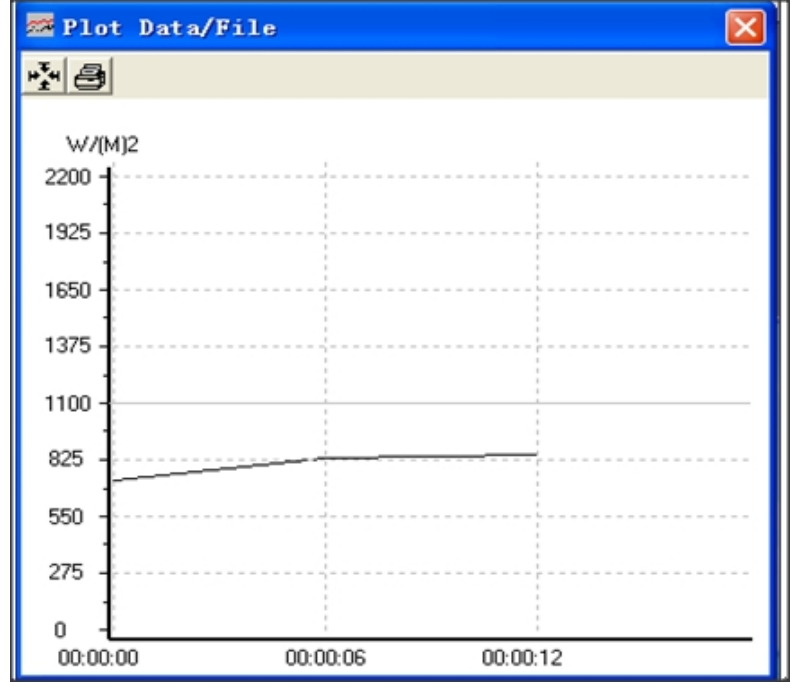

Figure 14. Sunlight intensity

The project operates in August 2014. The Hainan provincial price bureau recently, and officially approved TunChang modern agriculture photovoltaic (pv) power generation project to feed photovoltaic energy into electricity grids, and the online electricity price is $1.00 \mathrm{Yuan} / \mathrm{KWH}$ (tax included)[3].

The detection time is $9.25-10.15$ a.m., July 20,2016 . The surroundings temperature is $34{ }^{\circ} \mathrm{C}$, wind level is 3 at that time, and the sunlight intensity near panels $750-825 \mathrm{w} / \mathrm{m} 2$.

From above detection results, we can see that the temperature distribution of panels surface is above $38^{\circ} \mathrm{C}$, plants beside panels is $31-38^{\circ} \mathrm{C}, 33-48 \mathrm{w} / \mathrm{m} 2$ below panels. Temperature distribution of panels back side is $45-49^{\circ} \mathrm{C}$, temperature distribution of plants under panels is $33.4-36^{\circ} \mathrm{C}$.

The temperature distribution of plants in the green- house is $29.7-34^{\circ} \mathrm{C}$, photovoltaic panels back side $37.2-38.2^{\circ} \mathrm{C}$, acrylic board back side $48-49.6^{\circ} \mathrm{C}$. The sunlight intensity in the greenhouse $58-205 \mathrm{w} / \mathrm{m}^{2}$, which centered near $100 \mathrm{w} / \mathrm{m}^{2}$.

The temperature in the green- house is $33^{\circ} \mathrm{C}$ mostly, under panels $34^{\circ} \mathrm{C}$, the surroundings temperature is $34^{\circ} \mathrm{C}$.

The sunlight intensity in the greenhouse near $100 \mathrm{w} / \mathrm{m}^{2}, 33-48 \mathrm{w} / \mathrm{m}^{2}$ below panels, while the sunlight intensity $750-825 \mathrm{w} / \mathrm{m}^{2}$. So it's clear to see that the sunlight intensity is too weak for most plant to grow well, not to mention the high yield, and can only applies to part shade loving plant.

\section{Conclusions}

The construction of the project in line with the national industrial policy, promote energy conservation and reduce emissions, promote clean energy development in Hainan island.

The completion of the project can not only alleviate the pressure of the local energy shortage, at the same time will protect the environment, improve climate change, the project can provide 25 million degree clean energy a yea, can save 8200 tones standard coal a year compare with thermal power, or 11500 tons of raw coal, reduce carbon dioxide (CO2) emissions of 20000 tons, 160 tons of sulfur dioxide (SO2) emissions. Bring good economic benefits and social benefits for local, and will also be popularized to land tension region to construct photovoltaic power station. 
From the detection results, we can see that the total sunlight intensity inside the greenhouse or under panels is too weak for many plants to growth well. These detection results are very important for photovoltaic greenhouse design. The problem left to solve is how to consider both the photovoltaic power generation and plant yield above the same field. There are many problems need to be further studied, and now everything is still only in its infancy[4-7].

\section{Acknowledgements}

This work was financially supported by the Hainan Natural Science Foundation in 2016(Grant Number 20165198).

\section{References}

[1] http://www.solarzoom.com/article-71767-1.html

[2] http://gzw.hainan.gov.cn/sgzw/ssqy/qyjj/201508/t20150807_1633148.html

[3] http://www.ne21.com/news/show-70894.html

[4] http://guangfu.bjx.com.cn/special/?id=543117

[5] http://guangfu.bjx.com.cn/news/20160624/745328.shtml

[6] http://www.solarzoom.com/article-73301-1.html

[7] http://guangfu.bjx.com.cn/news/20160222/709780.shtml 